\title{
Optimization of Processes in a Freight Forwarding Company Using a Simulation Model
}

\author{
Michal Sedláček ${ }^{1, *}$ \\ ${ }^{1}$ College of Logistics, Přerov, Department of magister studies, Palackého 1381/25, 75002 Přerov, \\ Czech Republic
}

\begin{abstract}
This paper discusses the possibilities of optimizing processes in forwarding companies that provide services in international truck transport. The computer simulation model was used to optimize logistics processes in the real distribution company. Software SIMUL8 was chosen as a development environment for its possibility of dynamic discrete simulation of company processes. This model will help us to analyze bottlenecks in company processes and find optimal solutions using simulation experiments. Optimization is focused on the company's warehouse, where a sequence of vehicles loading and unloading operations and emerging downtime are explored.
\end{abstract}

\section{Introduction}

Simulation models can be used to optimize both external and internal business processes. Procedures and methods to optimize business processes are many $[1,2]$ and one of them is the use of computer modeling. This method can help us solve logistics problems such as minimizing inventory in stock, optimal utilization of handling equipment, shortening shipping routes and the introduction of lean production $[3,4]$. The simulations allow us to mimic processes that show shortcomings and bottlenecks. In the corporate process, we have to fix the problem and then propose its solution. The simulation is a cost-effective option for each company in terms of both financial and time-consuming. The company does not need to invest in the physical change of the process immediately, but after the simulation experiments and obtaining the necessary input data. Some methods, which use simulation models in solving logistic processes, were presented in [5-7].

Based on simulation experiments, we can easily identify bottlenecks at a particular point in the logistics process. If we find such a place, we can easily find solutions in the form of combinations to have the most effective impact on the whole simulation. The result of the simulation model should be to propose optimization of a particular process to solve the problem.

The paper focuses on solving the specific problem of eliminating the downtime of trucks in the forwarding company. This issue was solved in a specific forwarding company within the scope of the diploma thesis [8] at the College of logistics. The simulation model is used to obtain data for the decision-making process to eliminate truck downtime.

*Corresponding author: michal.sedlacek@,vslg.cz 


\section{Computer simulation}

Based on simulation experiments, we can easily identify bottlenecks at a particular point in the logistics process. If we find such a place, we can easily find solutions in the form of combinations to have the most effective impact on the whole simulation. The result of the simulation model should be to propose optimization of a particular process to solve the problem.

\subsection{Discrete simulation}

The discrete simulation model $[9,10]$ can be defined as a method of studying complicated probability dynamic systems through experiments in a computer model. Simulate means to mimic the operation of a real process using computer simulation. The complexity of the model is only a relative concept, which means that the model of a real process, cannot be solved by analytical steps, that will lead to a precise solution. With the whole model, we perform various experiments and observe the behavior of each activity. This is a statistical attempt, from which it follows that the result of the simulation is an estimate, not an exact meaning. Unlike a laboratory experiment, the simulation experiment is performed using a computer. The simulation as a scientific and practical field is closely related to the development of computer technology. Over time, simulation programs have been developed to simplify the production of simulation models in general. Thanks to these programs, we can easily perform simulation experiments and analysis of results.

Discrete simulation models are characterized, that all the state variables take only discrete values and change over time in jump steps [11-14]. Discrete dynamical system is a mathematical structure designed by main three components:

- Intervals in which all the possible values of the state variables lays,

- Function defined on specific interval,

- Differential equation which represents the "movement" equation of the system.

We quantify this change in terms of an updating function, which takes the current state of the system as an input, and specifies what the state of the system will be after some interval of time, an interval which corresponds to the specific updating function we are using. In general, an updating function is written:

$$
m_{t+1}=f\left(m_{t}\right),
$$

Where $m_{t}$ is the current state of the system, and $m_{t+1}$ is the state of the system after one interval of time has passed. By iterating the above calculation multiple times, we can find subsequent states of the system. Equation can be written in the form:

$$
f^{\circ} f\left(m_{t}\right)=f\left(f\left(m_{t}\right)\right)=f\left(m_{t+1}\right)=m_{t+2},
$$

This equation describes the changing states of the system in dependence on time. This equation is also used as a theoretical basis for understanding discrete time steps in simulation model that we created.

Simulation also serves to link the theoretical knowledge of probability, statistics, operational research, system theory and informatics. We can use it both to solve theoretical problems and to solve practical problems. Application of the simulation model may be for:

- analysis of the dynamic behavior of a complicated or projected enterprise system through computer simulation, 
- analysis of the sensitivity of the acquired solution to change the various parameters of the model,

- comparison of different system layout variants according to specified parameters for optimization of processes,

- replacing experiments with a business process that cannot be done in practice for some reason, but only by experiment using simulation.

Simulating means imitating the whole process just by computer simulation. The aim of the simulation is to solve specific situations or problems.

\subsection{Input preconditions of the simulation model}

To create the simulation model, a warehouse was selected, which is part of the entire logistic process of the company. In the warehouse the consignments are brought in during the week and the shipment ends at the end of the week and the consignments leave the warehouse.

The problem of downtime is solved in the warehouse. This problem occurs regularly every Friday and especially in traffic peak. At that moment a certain number of pick-up vehicles arrives and the warehouses are overwhelmed. This is mainly the capacity of warehouses and the number of loading ramps. Gradual steps have been compiled in simulation models using SIMUL8 simulation software to get the most accurate results. Data from these models were used for the final evaluation.

\subsection{Description of the simulation model}

The simulation model (Fig. 1) thoroughly examines the process of collecting consignments, especially the time-out of deliveries. The whole process works according to reality and the data entered into the simulation copies the real state of the system. The entire simulated process starts with the shipment of shipments from customers to the company terminal. This process is carried out using smaller vehicles. These vehicles are waiting for unloading, followed by unloading the pallets into the intermediate storage. As soon as the pallets are loaded into the intermediate storage, they are weighed into the warehouse shelves according to the destination. At this point, when all scheduled shipments are ready to be loaded, trucks arrive in to individual destinations. After loading all trucks, the model successfully ends with loading and leaving the last truck.

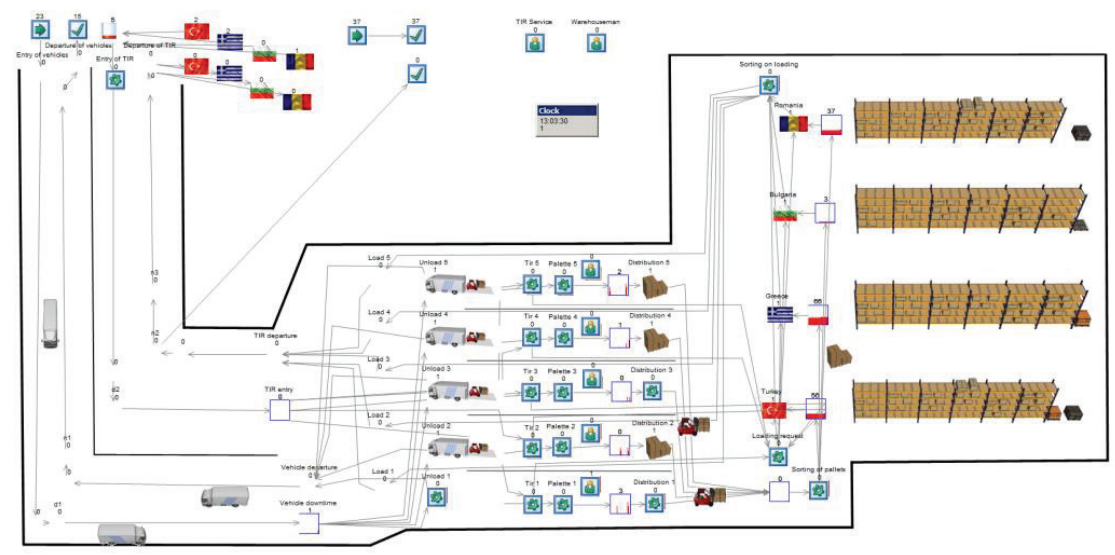

Fig. 1. Simulation model of the freight forward company. Source: authors 
The simulation begins at 7:00 AM when the warehouse opens and the warehouse staff is ready to go. This is a simulated expedition day and this was Friday. The simulation should end at 8:00 PM by leaving the warehouse and leaving the tenth truck. These data were determined based on the opening hours of the warehouse and the practical experience. However, this time is not fixed. Since this is a collection service, warehouse keepers are sometimes in the warehouse for longer because consignments are delayed or waiting for trucks.

\section{Creation of a simulation model}

The simulation model is composed of the following basic elements, which are the main building of the entire simulation project:

- Truck (Vehicle),

- Truck (TIR)

- Pallet,

- Warehouseman,

- Truck (TIR) service,

- Destination.

The basic elements of the model are truck, pallet and TIR. Vehicle arrivals are sorted by time. The first batch of trucks arrives in the warehouse is between 7:00 AM- 12:00 AM 8 cars in the interval of 37,5 minutes. In the time span, that lasts from 12:00 AMto 3:00 PM, 45 trucks arrive at the warehouse in the interval of 4 minutes. In the time span between 3:00 PM and 5:00 PM, only 7 trucks arrive at the warehouse in the interval of 17 minutes. In the simulation model, we investigate the time tip in the warehouse to find out the possible downtime in truck arrivals and try to design the optimal solution.

The warehouse has only 5 ramps and the warehouse capacity is limited. Friday is a critical day, and most of the week's raid is taking place. Using label action function in simulation model, we distinguish the destinations for trucks deliveries. There are three pallets in each. Shipments are sorted by destination destinations. These are Greece, Turkey, Romania and Bulgaria.

The inventory called "vehicle downtime" is the most important element in the simulation model. Penalties from carriers are set at $500 \mathrm{CZK}$ per hour if the truck waited without access to the ramp. Based on this data, a rate of $8.33 \mathrm{CZK}$ was set for every minute of the car's downtime. This rate is listed in the stack, so we'll figure out how much money the downtime of trucks will cost. Manipulation with pallets takes approximately 20 minutes. This time was determined based on measurements. Other activities, such as ramp arrival, pallet unloading, pallet marking and subsequent confirmation of documents by the carrier are included. After unloading the pallets into the intermediate warehouse, the pallets are unloaded into the final warehouse shelf. The pallets are sorted in front of the shelves by the pallet sorting.

In the simulation model there are 10 warehouses, the morning group is in the warehouse from 7:00 AMtill 3:30 PM, the afternoon group comes at 12:00 AMdue to the tip in the warehouse. From 3:30 PM, the warehouse is limited to 5 warehouses. An important point in the simulation is the arrival of the truck (TIR) to be loaded at 4:00 PM. All trucks are divided into four destinations: Greece, Turkey, Romania and Bulgaria. Each of the international trucks will pick up 33 pallets and the warehouseman will load the truck. Loading the truck takes about 66 minutes. Subsequently, the truck leaves the ramp and departs to a destination that has been pre-defined using the "Destination" label in simulation model. 


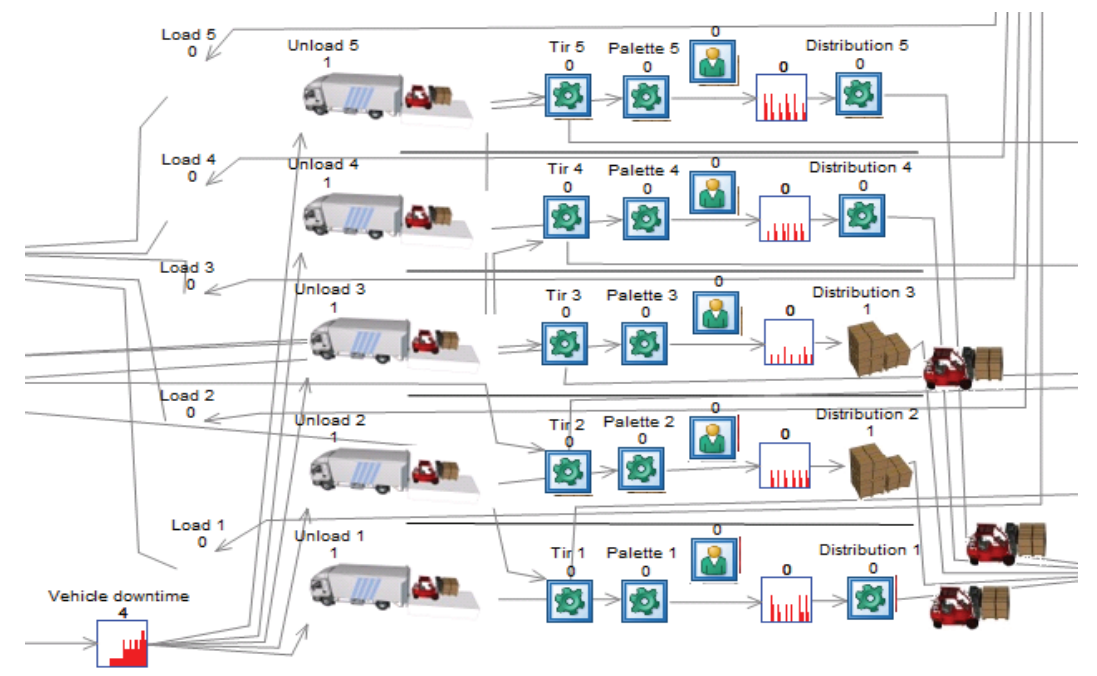

Fig.2. Part of the simulation model - problematic situation of the truck downtime. Source: authors

The result of the simulation is the apparent downtime of the trucks (vehicles) waiting to be unloaded listed in the vehicle downtime stack (Fig. 2). Another important feature is all served trucks and TIR. The sequence of all activities in the model is correctly defined and the final result is a functional simulation model corresponding to the real state of warehouse.

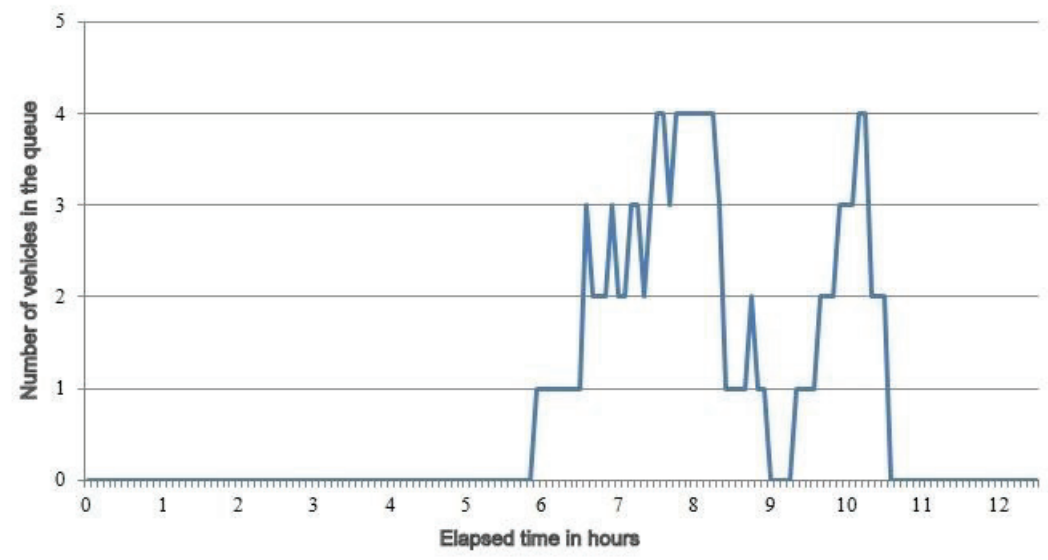

Fig. 3. The number of vehicles waiting in the queue (initial condition). Source: authors

\section{Simulation experiments}

A simulated model that matches the reality of the company will provide us with the current state of the system. We will focus mainly on arriving trucks to be unloaded and on trucks to be loaded to eliminate downtime, which is a financial burden of the company. The result of the simulation experiment is illustrated in Figure 3, which shows, that after 6 hours a queue of pick-up vehicles is being created, when there are 4 trucks waiting in the queue. This is a problematic situation, in terms of financial problem, it can become a company 4915, CZK 
each day. In simulation experiments, we will focus on eliminating this problematic downtime.

\subsection{Simulation experiment 1}

The first option to improve downtime is to add one warehouseman. He will help speed up the entire landing process, including TIR loading. An extra warehouseman is available from 12:00 AM. At the same time, there will come an extra warehouseman at 3:30 PM. The results of the simulation are shown in Figure 4.

The results show acceleration of the whole process and reduction of downtime. In total, the company would pay 500,-CZK for a day. In real terms, it is also necessary to count the possible financial costs for additional warehouseman, if the company would not solve it from its personnel resources, but by external staff.

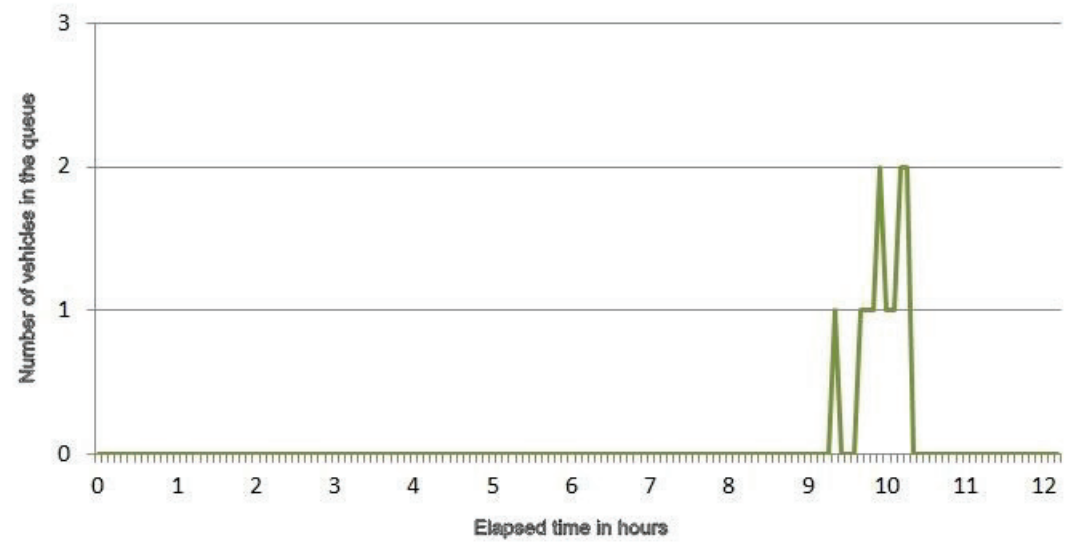

Fig.4. The number of vehicles waiting in the queue (Experiment 1). Source: authors

\subsection{Simulation experiment 2}

The second option is to shift the truck's arrival time to an earlier hour at 3:00 PM. However, this option will show clear deficiencies in the capacity of ramps and labor, which are considerably overloaded and disproportionately prolonged downtime. Generated graph on Figure 5 demonstrates this situation.

If we start loading trucks earlier, then higher downtime will occur. At this time, the simulation generated a loss of $1870,-\mathrm{CZK}$. The displacement of the loading time at 5:00 PM will also not solve the situation, the loss caused by the waiting truck donation is 3540,-CZK. 


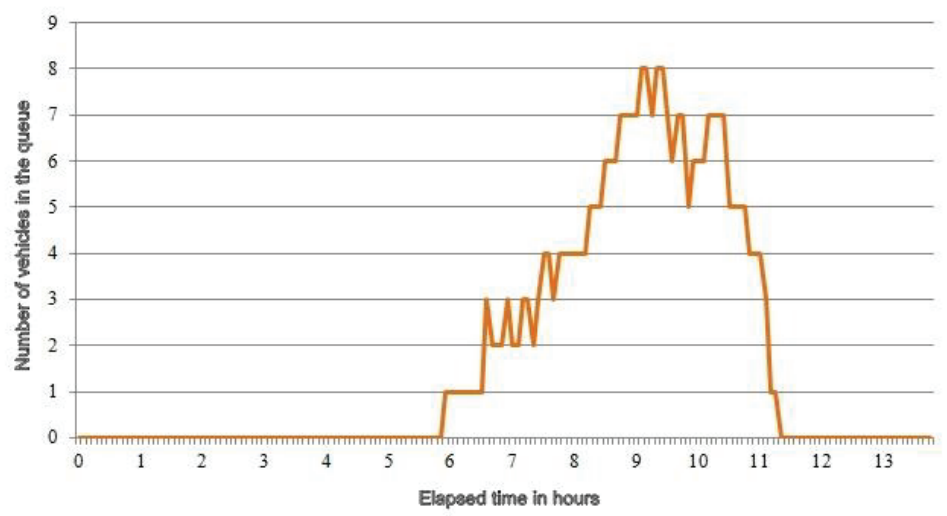

Fig. 1. The number of vehicles waiting in the queue (Experiment 2). Source: authors

\subsection{Simulation experiment 3}

Possible optimal solution to the current situation is a variation with the loading time at 5:00 PM and the addition of one warehouseman for loading. The result of this option is the zero time-lag of the trucks, but the possible additional labor costs. The last option is to add another loading ramp that could accelerate the entire loading process and reduce truck downtime. Adding the sixth ramp could help the current situation, but unfortunately it does not seem like a real deal in today's business conditions. There is no room for expansion in the warehouse, and the owner would not allow it either. This option can only be created in the simulation model.

Table 1. Costs of truck waiting times according to simulation experiments. Source: authors

\begin{tabular}{|l|c|c|c|}
\hline & $\begin{array}{c}\text { Arrival time of } \\
\text { TIR }\end{array}$ & $\begin{array}{c}\text { Total waiting time } \\
\text { for all trucks }\end{array}$ & $\begin{array}{c}\text { Cost of truck } \\
\text { downtime }\end{array}$ \\
\hline Experiment 1 & 4:00 PM & $60 \mathrm{~min}$ & $500,-$ CZK \\
\hline Experiment 2.1 & $3: 00 \mathrm{PM}$ & $225 \mathrm{~min}$ & $1870,-$ CZK \\
\hline Experiment 2.2 & 5:00 PM & $425 \mathrm{~min}$ & $3540,-$ CZK \\
\hline
\end{tabular}

\section{Conclusion}

The simulation model, which was constructed and on which experiments were performed, provided data to assess the suitability of the proposed optimization variant. The problem was related to the downtime of vehicles in the warehouse. The experiments consisted of a change in the number of workers in the warehouse and the arrival time of the lorries to load the goods. As an optimal solution, the option was chosen to change the time of arrival of trucks and to add one labor force to the warehouse. This option is optimal especially if the trucking company uses its own resources - unused workforce.

Possibilities of using of the simulation models in praxis are large. Simulation models can be used with advantage in dealing with different logistical problems. As example can be the models of production logistics, distribution logistics, reverse logistics, transportation logistics and logistics services $[4,5,15]$. In other fields simulation models are used to solve problems of crisis management and obtaining input data for solving various problems of human activities $[6,7,16]$. Simulation tools occupy an important place in improving the efficiency of logistics processes of companies, among them we can mention the so-called 
digital factory $[13,17]$ and production information systems based on an internet of things [3].

The aim of this paper is to demonstrate the specific use of simulation models for solving the truck downtime in freight forwarding company. This problem was solved in a manufacturing enterprise and subsequently realized. Simulation model was served as a basis for strategic decisions of the company management. The paper describes three variants of solving the truck downtime, describes the assembly simulation experiments, execution and evaluation of the different options according to the simulation results. Simulation models have been used in solving the specific logistical problem in the real company.

This paper is supported by the research project "From horse-drawn railway to intermodal transport" within Visegrad Fund.

\section{References}

1. G. Fedorko, Z. Čujan, 12th International Conference on Industrial Logistics, 167-175 (Island Brac, Croatia, 2014)

2. G. Fedorko, V. Molnár, J. Strohmandl, M. Vasil', Transport Means 2015, 466-469 (Kaunas University of Technology, Lithuania, 2015)

3. T. Martoch, O. Kodym, SGEM 2013 - International Multidisciplinary Scientific GeoConference Surveying Geology and Mining Ecology Management, 207-212 (Albena, Bulgaria, 2013)

4. M. Andrejiová, A. Pavlisková, N. Husáková, Carpathian Logist. Congr., 1-6 (Tanger LTD. Ostrava, Czech Republic, 2012)

5. O. Kodym, L. Kavka, M. Sedláček, SGEM 2015 - International Multidisciplinary Scientific GeoConference Surveying Geology and Mining Ecology Management, 183190 (Albena, Bulgaria, 2015)

6. G. Fedorko, N. Husáková, G. Dudáš, Acta Montan. Slovaca 15, 14-22 (2010)

7. V. Molnár, Carpath. Logis. Congr., 1-6 (Tanger LTD: Ostrava, Czech Republic, 2012)

8. J. Vyšín, Optimalizace procesů ve spediční společnosti s využitím simulačních modelì (Diploma thesis, College of logistics, Přerov, Czech Republic, 2017)

9. M. Dlouhý, Simulace podnikových procesů (Brno: C. Press, Czech Republic, 2007)

10. I. Křivý, E. Kindler, Simulace a modelování (Ostrava: OU, Czech Republic, 2001)

11. R. Bartošíková, J. Bilíková J. Strohmandl, V. Šefčík, P. Taraba, 24th International Business Information Management Association Conference, 1479-1483 (Milano, Italy, 2014)

12. S. Li, X. Wang, International Journal of Control and Automation 8, 2, 71-82 (2015)

13. H. Neradilova, G. Fedorko, Acta Logistica Moravica 1, 36-43 (2015)

14. SIMUL8, Corporation. Simul8: manual and simulation guide (Herndon, VA: The Corporation, 2001)

15. A. Torok, A. Torok, F. Heinitz, Transport and Telecommunications 15, 4, 292-298 (2014)

16. M. Čičak, T. Mlinarić, B. Abramović, Promet - Traffic - Traffico 16, 2, 63-69 (2004)

17. J. Nikolic, I. Ristovic, D. Vasovic, Journal of Environmental Protection and Ecology 16, 3, 1082-1090 (2015) 